Timing Matters: Change Depends on the Stage of Treatment in Cognitive Behavioral Therapy for Panic Disorder with Agoraphobia

Gloster, Andrew T. ${ }^{1,2}$, Klotsche, Jens ${ }^{1,3}$, Gerlach, Alexander L. ${ }^{4}$, Hamm, Alfons ${ }^{5}$, Ströhle, Andreas $^{6}$, Gauggel, Siegfried ${ }^{7}$, Kircher, Tilo $^{8}$, Alpers, Georg W. ${ }^{9}$, Deckert, Jürgen $^{10}$, \& Wittchen, Hans-Ulrich ${ }^{1}$.

${ }^{1}$ Technische Universität Dresden, Germany

${ }^{2}$ University of Basel, Switzerland

${ }^{3}$ German Rheumatism Research Centre Berlin, a Leibniz Institute

${ }^{4}$ University of Cologne, Germany

${ }^{5}$ Ernst Moritz Arndt University of Greifswald, Germany

${ }^{6}$ Charité-Universitätsmedizin Berlin, Germany

${ }^{7}$ University of Aachen, Germany

${ }^{8}$ Philipps-University Marburg, Germany

${ }^{9}$ University of Mannheim, Germany

${ }^{10}$ University of Würzburg, Germany

PAPER ACCEPTED AND PUBLISHED BY JOURNAL OF CONSULTING AND CLINICAL PSYCHOLOGY - FOR CONFIDENTIAL INTERNAL USE ONLY

Gloster, A. T., Klotsche, J., Gerlach, A. L., Hamm, A., Ströhle, A., Gauggel, S., ... Wittchen, H. (2014). Timing matters: Change depends on the stage of treatment in Cognitive Behavioral Therapy for Panic Disorder with Agoraphobia. Journal of Consulting and Clinical Psychology, 82, 141-153. doi: 10.1037/a0034555

Acknowledgments:

Funding/Support: This work is part of the German multicenter trial "Mechanisms of Action in CBT (MAC)". The MAC study is funded by the German Federal Ministry of Education and Research (BMBF; project no. 01GV0615) as part of the BMBF Psychotherapy Research Funding Initiative.

Centers: Principal investigators (PI) with respective areas of responsibility in the MAC study are V. Arolt (Münster: Overall MAC Program Coordination), H.U. Wittchen (Dresden: Principal Investigator (PI) for the Randomized Clinical Trial and Manual Development), A. Hamm (Greifswald: PI for Psychophysiology), A.L. Gerlach (Münster: PI for Psychophysiology and Panic subtypes), A. Ströhle (Berlin: PI for Experimental Pharmacology), T. Kircher (Marburg: PI for functional neuroimaging), and J. Deckert (Würzburg: PI for Genetics). Additional site directors in the RTC component of the program are G.W. Alpers (Würzburg), T. Fydrich and L.Fehm (Berlin-Adlershof), and T. Lang (Bremen).

Data Access and Responsibility: All principle investigators take responsibility for the integrity of the respective study data and their components. All authors and co-authors had full access to all study data. Data analysis and manuscript preparation were completed by the authors and co-authors of this article, who take responsibility for its accuracy and content.

Acknowledgements and staff members by site: Greifswald (coordinating site for psychophysiology): Christiane Melzig, Jan Richter, Susan Richter, Matthias von Rad; Berlin-Charite (coordinating center 


\section{TIMING MATTERS}

for experimental pharmacology): Harald Bruhn, Anja Siegmund, Meline Stoy, Andre Wittmann; Berlin-Adlershof: Irene Schulz; Münster (Overall MAC Program Coordination, Genetics and Functional Neuroimaging):Andreas Behnken, Katharina Domschke, Adrianna Ewert, Carsten Konrad, Bettina Pfleiderer, Peter Zwanzger Münster (coordinating site for psychophysiology and subtyping):, Judith Eidecker, Swantje Koller, Fred Rist, Anna Vossbeck-Elsebusch; Marburg/Aachen (coordinating center for functional neuroimaging):, Barbara Drüke, Sonja Eskens, Thomas Forkmann, Siegfried Gauggel, Susan Gruber, Andreas Jansen, Thilo Kellermann, Isabelle Reinhardt, Nina Vercamer- Fabri; Dresden (coordinating site for data collection, analysis, and the RCT): Franziska Einsle, Christine Fröhlich, Andrew T. Gloster, Christina Hauke, Simone Heinze, Michael Höfler, Ulrike Lueken, Peter Neudeck, Stephanie Preiß, Dorte Westphal; Würzburg Psychiatry Department (coordinating center for genetics): Andreas Reif; Würzburg Psychology Department: Julia Dürner, Hedwig Eisenbarth, Antje B. M. Gerdes, Harald Krebs, Paul Pauli, Silvia Schad, Nina Steinhäuser; Bremen: Veronika Bamann, Sylvia Helbig-Lang, Anne Kordt, Pia Ley, Franz Petermann, Eva-Maria Schröder. Additional support was provided by the coordinating center for clinical studies in Dresden (KKS Dresden): Xina Grählert and Marko Käppler.

The RTC project was approved by the Ethics Committee of the Medical Faculty of the Technical University of Dresden (EK 164082006). The neuroimaging components were approved by the Ethics Committee of the Medical Faculty of the Rheinisch-Westfälische Hochschule University Aachen (EK 073/07). The experimental pharmacology study was approved by the Ethics Committee of the state of Berlin (EudraCT: 2006-00-4860-29).

The study was registered with the ISRCTN: ISRCTN80046034.

Correspondence concerning this article should be addressed to:

Andrew T. Gloster

University of Basel

Division of Clinical Psychology and Epidemiology

Missionsstrasse 62A

CH-4055 Basel

Switzerland

Tel: ++41-61-267-0275

Email: andrew.gloster@unibas.ch 


\title{
TIMING MATTERS
}

\begin{abstract}
Objective: The mechanisms of action underlying treatment are inadequately understood. This study examined five variables implicated in the treatment of Panic Disorder with Agoraphobia (PD/AG): catastrophic agoraphobic cognitions, anxiety about bodily sensations, agoraphobic avoidance, anxiety sensitivity, and psychological flexibility. The relative importance of these process variables was examined across treatment phases: 1) psychoeducation/ interoceptive exposure; 2) in situ exposure; 3) generalization/ follow-up.
\end{abstract}

Method: Data came from a randomized controlled trial of CBT for PD/AG $(n=301)$.

Outcomes were the Panic Agoraphobia Scale (PAS) and functioning as measured in the Clinical Global Impression (CGI). The effect of process variables on subsequent change in outcome variables was calculated using bivariate latent difference score modeling.

Results: Change in panic symptomatology was preceded by catastrophic appraisal and agoraphobic avoidance across all phases of treatment; by anxiety sensitivity during generalization/ follow-up; and psychological flexibility during exposure in situ. Change in functioning was preceded by agoraphobic avoidance and psychological flexibility across all phases of treatment; fear of bodily symptoms during generalization/ follow-up; and anxiety sensitivity during exposure.

Conclusions: The effects of process variables on outcomes differ across treatment phases and outcomes (i.e., symptomatology vs. functioning). Agoraphobic avoidance and psychological flexibility should be investigated and therapeutically targeted in addition to cognitive variables.

Keywords: Mechanism of Action, CBT, Panic Disorder, Agoraphobia, Avoidance, Psychological Flexibility 


\section{TIMING MATTERS}

Timing Matters: Change Depends on the Stage of Treatment in Cognitive Behavioral Therapy for Panic Disorder with Agoraphobia

The efficacy of Cognitive Behavioral Therapy (CBT) for Panic Disorder (PD) and Agoraphobia (AG) is undeniable, yet the crucial task of elucidating the mechanisms of action lags behind. Far from an abstract theoretical concern, understanding the mechanisms of action of treatment would provide knowledge on how to generalize the principles utilized in treatment studies and offer hope for the sizable minority of patients that do not respond to current treatments (Hofmann \& Smits, 2008) by amplifying those specific processes known to affect outcome. Towards this aim, conceptual and methodological clarity are crucial.

Much theoretical and empirical work has been devoted to explaining the nature and treatment of PD and AG. Cognitive accounts suggest that catastrophic misinterpretation of bodily sensations influences the etiology and maintenance of PD and AG (Clark, 1986). Cognitive therapy thus targets the content and frequency of associated thoughts through numerous methods. Anxiety Sensitivity, or the fear of anxiety and fear, has also been conceptualized as a risk factor associated with the subsequent onset of panic disorder (Ehlers, 1995), and with avoidance behaviors (Zvolensky \& Forsyth, 2002). Anxiety sensitivity is consequently considered an important therapeutic target for PD/AG (Smits, Powers, Cho, \& Telch, 2004) achieved through various means including interoceptive exposure. However, the pernicious effects of both cognitive appraisals and anxiety sensitivity depend in part on how an individual attempts to regulate their negative affect (Kashdan, Zvolensky, McLeish, 2008). This suggests that successful therapy must also target the way one interacts with these negative appraisals, beliefs, and emotions.

A common regulation strategy for these negative appraisals and emotions is avoidance. Indeed, agoraphobic avoidance, or the avoidance of feared situations, is a defining feature of agoraphobia (Chambless, Caputo, Jasin, Gracely, \& Williams, 1985) even in the 


\section{TIMING MATTERS}

absence of PD (Wittchen et al., 2008; Wittchen, Gloster, Beesdo-Baum, Fava, \& Craske, 2010). Although not always explicitly targeted (Hofmann \& Spiegel, 1999), reduction of agoraphobic avoidance is a common therapeutic target and is associated with successful outcome (Gloster et al., 2011). Another regulatory strategy recently implicated in PD/AG is psychological flexibility. Psychological flexibility refers to the ability to mindfully accept cognitions and emotions when doing so is useful for living a meaningful life (Bond et al., 2011). Similar to anxiety sensitivity, psychological flexibility is not exclusively relevant to PD/AG, yet has been implicated in panic-related distress (Karekla, Forsyth, \& Kelly, 2004), baseline functioning in anxiety disorders (Gloster, Klotsche, Chaker, Hummel, \& Hoyer, 2011), treatment outcome (Forman, Herbert, Moitra, Yeomans, \& Geller, 2007), and is conceptually distinct from anxiety sensitivity in patients with PD/AG (Kämpfe et al., 2012).

Given that appraisal of anxiety symptoms, anxiety sensitivity, avoidance, and psychological flexibility are all associated with various aspects of $\mathrm{PD} / \mathrm{AG}$, it is important to understand to what degree some or all these constructs are active mechanisms for successful treatment outcome. Mediation analysis (Baron \& Kenny, 1986) has emerged as one important analytical procedure for the critical testing of putative mechanisms of action in therapy (Kazdin, 2007) and a handful of formal mediation analyses have been conducted across variations of CBT for PD/AG (e.g., group vs. individual therapy). These studies provide positive evidence for the mediating or partially mediating role of cognitive content, cognitive appraisal, and self-efficacy (Casey, Newcombe, \& Oei, 2005; Hofmann et al., 2007, Meulenbeek, Spinhoven, Smit, Van Balkom, \& Cuijpers, 2010; Vögele et al., 2010) and anxiety sensitivity (Smits, Powers, Cho, \& Telch, 2004) in reducing the severity of panic disorder. Although an important step towards isolating active mechanisms, these findings are limited by the fact that the assessment of target variables did not precede outcome assessments. That is, the process variables were tested concurrently with the outcome measure (e.g., both measured pre - post). This lack of temporal order hinders interpretation because it 


\section{TIMING MATTERS}

is unclear if the outcome variables also influence the process variables and because such designs leave open the possibility that process variables exert their effects at different points during the therapy.

Longitudinal temporal testing of putative mechanisms within the course of treatment for PD/AG has been examined only in a few studies. In one such study, 12 patients diagnosed with PD/AG completed daily diaries for 30 weeks (Bouchard et al., 2007). CBT was administered in groups and emphasized either cognitive or exposure interventions. Daily dairies were used to assess beliefs about the consequences of panic, self-efficacy to control panic attacks in the face of bodily sensations and catastrophic thoughts, and anticipatory anxiety about having a panic attack that day. During the course of therapy, all 12 patients recorded changes in their beliefs and level of self-efficacy prior to recording changes in anticipatory anxiety, irrespective of condition. Despite the small sample size, this study demonstrated with temporal sensitivity that changes in cognitive variables preceded change in other aspects of symptomatology for all patients, though the magnitude of change differed across patients.

To our knowledge, only a few further studies temporally examined whether salient process variables preceded subsequent change in panic-related outcomes. Using cognitive therapy and guided mastery - both administered in a group format - Hoffart (1995) examined the relevance of self-efficacy, catastrophic beliefs, and perceived control of thoughts on subsequent fear in a behavioral avoidance test (BAT). Results from the 46 patients included in the study indicated that change in self-efficacy was the strongest and most consistent predictor of subsequent change in fear during the BAT. A second study (Teachman, Marker, \& Clerkin, 2010) examined whether catastrophic misinterpretations subsequently affected various facets of panic symptomatology. Panic control treatment was administered in a group format to 43 patients. Using bivariate difference score modeling analysis, results indicated that change in catastrophic misinterpretation predicted subsequent change in panic 


\section{TIMING MATTERS}

symptomatology. The reverse pattern (i.e., symptomatology predicting subsequent change in catastrophic misinterpretation) was not consistently found except for distress/ apprehension. A final study examined cognitive process variables during the first phase of treatment (i.e., four weeks) in 41 patients diagnosed with PD/AG (Meuret, Rosenfield, Seidel, Bhaskara, \& Hofmann, 2010) across two distinct treatment conditions. Process variables were operationalized as a composite score of questionnaires that measure anxiety sensitivity/ fear about the consequences of panic (i.e., anxiety sensitivity index (ASI) and body sensation questionnaire (BSQ), respectively) in addition to perceived control. During the phase of treatment examined, patients received either cognitive treatment or capnometry-assisted respiratory training. So designed, the specificity of the cognitive process variables could be tested across relatively pure intervention conditions. Indeed, results suggested that cognitions were bidirectionally associated with changes in panic severity only in the cognitive training condition whereas perceived control was bidirectionally associated with panic symptom change in both conditions. This excellent study included information only from the first half of treatment (four weeks), however, thus limiting information about how mechanisms unfold over the full course of treatment or generalize following treatment. Taken together, these studies provide strong support for the role of cognitively oriented process variables defined as catastrophic misinterpretations and self-efficacy in the prediction of subsequent change in symptomatology.

To our knowledge, no other PD/AG relevant process variables than those discussed above (i.e., feared consequences / anxiety sensitivity and self-efficacy/ perceived control to cope with panic) have been tested. Examination and direct comparison of other variables implicated in the treatment of PD/AG such as avoidance behavior and psychological flexibility is a crucial step in the process of understanding the mechanisms of treatment (Kazdin, 2007). 


\section{TIMING MATTERS}

In addition to expanding the scope of process variables under investigation, outcome variables also need to be expanded. To date, all process studies examined the effect on panicrelated variables, but only one examined how putative mechanims affect other outcomes such as functioning (Smits et al., 2004). It remains an open question whether the mechanisms of action involved in symptom reduction are identical in importance and sequence to those involved in other treatment targets. Social, occupational, and psychological functioning are certainly related to symptomatology, yet it is a broader measuring stick. Indeed, the impetus for patients to seek therapy may be primarily related to functioning and in our quest to better understand mechanisms care should be taken not to reduce patients to their symptomatology.

This purpose of the present study was to investigate the degree to which five process variables affect treatment outcome across the active and follow-up phases of a standardized CBT for PD/AG. Towards this end, the process variables were examined across phases of therapy for two outcomes: severity of PD/AG symptomatology and overall functioning. The process variables were examined longitudinally using bivariate latent difference score modeling to determine the relative effects of the process variables at different points in the therapeutic process. So doing, the relative importance of the process variables were examined for their relationship to different components of the therapy. We hypothesized that the variables would differentially predict subsequent symptoms as a function of treatment phase (i.e., psychoeducation, functional analysis, interoceptive exposure [pre-treatment to intermediate assessment following the $4^{\text {th }}$ session]; exposure in situ, anticipatory anxiety and specified interoceptive exposure [intermediate assessment to post-treatment following the $12^{\text {th }}$ session]; and generalization period with two booster sessions that reviewed progress, helped set goals, and addressed difficulties [post-treatment to 6-month follow-up period]) and outcome variable (panic and agoraphobia symptoms vs. functioning). Specifically, we predicted that a) cognitive appraisal would predict subsequent change in panic symptoms, but not functioning, only during sessions 1-4 because these sessions addressed psychoeducation 


\section{TIMING MATTERS}

and engaged the patient intellectually; b) anxiety elicited by bodily symptoms would predict subsequent change in panic symptom, but not functioning, only during sessions 1-4 because these sessions introduced interoceptive exposure; c) anxiety sensitivity would predict subsequent change panic symptoms during sessions 1-12 because of interoceptive exposure during the first 4 sessions and exposure in situ during $2^{\text {nd }}$ half of treatment and functioning during treatment because improvement in function is likely related to a new relationship with the anxiety; d) avoidance behavior would predict subsequent change in both panic symptoms and functioning across sessions 1-12 and the follow-up period because avoidance was directly and intensively targeted in the therapy as a maintaining factor, and e) and psychological flexibility would predict subsequent change in panic symptoms during sessions 5-12 because it is believed to facilitate exposure and functioning during all phases because it is closely tied to functioning.

\section{Methods}

\section{Design}

Data were collected within the Mechanisms of Action for CBT (MAC) study. The MAC study was a multicenter, randomized controlled trial for patients with PD/AG. The methods and main outcomes of the study were published elsewhere (Gloster et al., 2009; Gloster et al., 2011). The MAC study was approved by the internal review board of all relevant institutions. The current study included all patients $(n=369)$, but the longitudinal analyses were limited only to those patients who received treatment $(n=301)$. Thus, the $n=$ 68 waitlist patients were excluded from this set of analyses.

\section{Participants}

All patients met Diagnostic and Statistical Manual of Mental Disorders (4th ed., text rev.; DSM-IV-TR; American Psychiatric Association, 2000) diagnostic criteria for PD with AG, scored $\geq 18$ on the Hamilton Anxiety Scale (HAM-A), and $\geq 4$ on the Clinical Global Impression Scale (CGI). Other current comorbid diagnoses, including unipolar depression and 


\section{TIMING MATTERS}

other anxiety disorders, were allowed unless they were of primary clinical concern. Over $90 \%$ of the sample had at least one comorbid condition, with nearly half the sample diagnosed with two or more mental disorders in addition to PD/AG. The most frequent comorbid conditions were specific phobia $(n=214 ; 71.1 \%)$, harmful use/abuse of alcohol $(n=135 ; 44.9 \%)$, social phobia $(n=126 ; 42.4 \%)$, and major depression $(n=118 ; 39.2 \%)$. As such, this sample can be considered both relatively severe and representative of patients seen in clinical practice. All patients were free from psychopharmacological medication. Extensive details about inclusion and exclusion criteria have been previously published (Gloster et al., 2009; Gloster et al., 2011).

The 301 patients in this study had a mean age of 35.5 (10.7). A majority of patients were women $(n=228,75.8 \%)$ and $131(43.5 \%)$ had at least some higher education. Nearly a third were married $(n=98,32.7 \%)$, half were single $(n=165,55.0 \%)$, and the rest were divorced or widowed. Consistent with the demographic characteristics of the population from which these data were sampled, all participants were of Caucasian origin.

\section{Treatment}

Patients received a 12-session manualized treatment protocol (Lang, Helbig-Lang, Westphal, Gloster, \& Wittchen, 2011), implemented over 6 weeks, and followed by two booster sessions. Sixty-three certified therapists, all of whom were either advanced graduate students or post-docs, administered treatment. All therapists went through a thorough training and certification procedure. Treatment integrity, training, randomization, and further design issues are published elsewhere (Gloster et al., 2011).

The treatment was highly efficacious (Gloster et al., 2011) and consisted of three phases: 1) psychoeducation, individualized behavioral analysis, rationale for exposure, interoceptive exposure exercises (sessions 1-4); 2) standardized in-situ exposure exercises, anticipatory anxiety, individualized in situ exposure exercises (sessions 5-12); and 3) the generalization period through the 6-month follow-up assessment. The study had two active 


\section{TIMING MATTERS}

treatment groups that varied only with respect to the implementation of a single component (in situ exposure with [T+] vs. without [T-] the therapist present), but not content. No relaxation exercises, breathing retraining, or explicit logical empiricism and disconfirmation of thoughts were undertaken in either group.

\section{Assessment}

Measures were assessed pre-treatment, at the intermediate point in treatment (between the $4^{\text {th }}$ and $5^{\text {th }}$ sessions), post-treatment (after the $12^{\text {th }}$ session), and at the 6-month follow-up, which occurred 6 months after the post-treatment assessment. The one exception is the anxiety sensitivity index, which was not measured at the intermediate assessment.

\section{PD/AG symptomatology and clinical functioning.}

Panic and Agoraphobia Scale (PAS; Bandelow, 1997). The PAS is a patient selfreport, 13-item questionnaire that measures the severity of panic attacks, avoidance, anticipatory anxiety, disability, and worries about health. All items are scored from 0 to 4. Scores on the PAS have have good reliability and are sensitive to change (Bandelow, 1997; Gloster et al., 2011). The internal consistency of the PAS in this sample was $\alpha=0.86$.

\section{Clinical Global Impression Scale - Severity Subscale - Functioning Item (CGI;}

Guy, 1976). CGI is a clinician-rated scale that measures the overall severity of a disorder, with scores that range between 1 (no disorder) and 7 (among the most severely ill patients). The scale normally queries for information across the facets of panic symptoms, anxiety, anticipatory anxiety, avoidance, and overall functional level before making the global rating. Scores on the CGI are sensitive to change in panic treatment (Barlow et al., 2000; Gloster et al., 2011). For this study we only used the one item measuring overall functioning in order to maximize conceptual distinctness from the PAS.

\section{Process Variables.}

Agoraphobic Cognitions Questionnaire (ACQ; Chambless, Caputo, Bright, \&

Gallagher, 1984). The ACQ is a 14-item self-report questionnaire that measures the 


\section{TIMING MATTERS}

frequency of catastrophic beliefs about the possible consequences of experienced anxiety and panic. Each item is rated on a five-point scale, ranging from 1 (never) to 5 (always). The ACQ has sound psychometrics and is a standard assessment in PD/AG research (Zgourides, Warren, \& Englert, 1989). The internal consistency of the ACQ in this sample was $\alpha=0.74$.

Bodily Sensations Questionnaire (BSQ; Chambless et al., 1984). The BSQ is a 17 item self-report questionnaire that measures the degree of anxiety elicited by body sensations. Each item is rated on a five-point scale, ranging from 1 (not at all) to 5 (extremely). The BSQ has sound psychometrics and is a standard assessment in PD/AG research (Zgourides, Warren, \& Englert, 1989). The internal consistency of the BSQ in this sample was $\alpha=0.87$.

Mobility Inventory (MI; Chambless, Caputo, Jasin, Gracely, \& Williams, 1985). The MI is a self-report questionnaire that measures the degree to which 27 situations are avoided. Items are scored from 1 (never avoid the situation) to 5 (always avoid the situation), with the mean of all items as the total score. Scores of the MI are highly reliable and sensitive to change (Chambless et al., 1985; Gloster et al., 2011). For this study, only the ratings for the "alone" subscale are utilized. The internal consistency of the MI in this sample was $\alpha=0.93$.

Anxiety Sensitivity Inventory (ASI; Peterson \& Reiss, 1993). The ASI is a 16-item self-report questionnaire that measures beliefs about potential harmful consequences of anxiety related symptoms. Each item is rated on a five-point scale from 0 (very little) to 4 (very much). The ASI has demonstrated sound psychometrics and is associated with various indices of PD/AG and other anxiety disorders (Rodriguez, Bruce, Pagano, Spencer, \& Keller, 2004). The internal consistency of the ASI in this sample was $\alpha=0.86$.

Acceptance and Action Questionnaire - II (AAQ-II;Bond et al., in press). The AAQII is a 7-item self-report questionnaire that measures psychological flexibility. Each item is rated on a seven-point scale from 1 (never true) to 7 (always true). The AAQ-II has demonstrated sound psychometrics and is associated with various indices of PD/AG and other 


\section{TIMING MATTERS}

anxiety disorders, with good discriminant validity (Bond et al, 2011; Gloster et al., 2011).

The internal consistency of the AAQ-II in this sample was $\alpha=0.94$.

\section{Statistical Analyses}

Lower level mediation analyses were conducted to investigate the association of the five process variables ACQ, BSQ, MI, ASI, AAQ-II and the change in treatment outcomes PAS and CGI over time (Kenny, Korchmaros, \& Bolger, 2003) as a preliminary step in data analyses. The associations were estimated by Multilevel linear mixed models with time as predictor variable, the five process variables ACQ, BSQ, MI, ASI and AAQ-II as time varying covariates and PAS and CGI as outcomes (Kenny, Korchmaros, \& Bolger, 2003; Singer \& Willet, 2003).

Latent difference score (LDS) models provide a tool where change and individual differences in change are represented in the model (Selig \& Preacher, 2009). LDS incorporates features of latent growth curve modeling and cross-lagged regression models. We only shortly describe our analytic strategy, a detailed presentation of the theory can be found in McArdle \& Nesselroade (1994) or Hawley, Ho, Zuroff \& Blatt (2006). We evaluated different univariate LDS models for the change of PAS, CGI, ACQ, BSQ, ASI, AAG-II and MI over time for investigating the nature of change in a first step. The latent change in a repeatedly observed score $Y$ in an individual $n$ at time $t$ can be expressed by

$$
\Delta y(t)_{n}=y(t)_{n}-y(t-1)_{n}=\alpha_{y} S_{y n}+\beta_{y} y(t-1)_{n},
$$

where the observed score $Y(t)_{n}$ can be decomposed into a true score $\mathrm{y}(\mathrm{t})_{\mathrm{n}}$ and a measurement error $\mathrm{e}_{\mathrm{n}}$ with a mean of zero and a positive variance. The latent change in $Y$ is the sum of two components in equation (1), an additive $\left(\alpha_{n} s_{y n}\right)$ and a proportional $\left(\beta_{y} y(t-1)_{n}\right)$ change component. The coefficient $s_{y n}$ corresponds to an intercept in the equation, which may vary across individuals and is constant over time. The $\alpha$ coefficient is a factor loading and fixed to one for model identification purposes. The coefficient $\beta_{y}$ represents the proportional effect of the previous latent variable on the change rate. We compared univariate LDS models for time- 


\section{TIMING MATTERS}

invariant and time-varying proportional coefficients $\beta_{y}$ as well as a no change score LDS model $\left(\Delta y(t)_{n}=0, \alpha_{y}=\beta_{y}=0\right.$ in equation 1$)$ for each considered score. The univariate LDS models where combined to establish bivariate LDS in a second step. Bivariate LDS models provide an appealing feature for investigating whether one score is the leading indicator of change in the other variable. A coupling parameter $\gamma$ is included into the equations of two univariate LDS models representing the effect of one score on the rate of change in the other. The bivariate LDS model with an other score $z(t)$ at time $t$ can be written by

$$
\begin{aligned}
& \Delta \mathrm{y}(\mathrm{t})_{\mathrm{n}}=\mathrm{y}(\mathrm{t})_{\mathrm{n}}-\mathrm{y}(\mathrm{t}-1)_{\mathrm{n}}=\alpha_{\mathrm{y}} \mathrm{Syn}_{\mathrm{n}}+\beta_{\mathrm{y}} \mathrm{y}(\mathrm{t}-1)_{\mathrm{n}}+\gamma_{\mathrm{z}} \mathrm{z}(\mathrm{t}-1)_{\mathrm{n}} \\
& \Delta \mathrm{z}(\mathrm{t})_{\mathrm{n}}=\mathrm{z}(\mathrm{t})_{\mathrm{n}}-\mathrm{z}(\mathrm{t}-1)_{\mathrm{n}}=\alpha_{\mathrm{z}} S_{\mathrm{zn}}+\beta_{\mathrm{z}} \mathrm{z}(\mathrm{t}-1)_{\mathrm{n}}+\gamma_{\mathrm{y}} \mathrm{y}(\mathrm{t}-1)_{\mathrm{n}} .
\end{aligned}
$$

The relationship between the two dual change LDS models is given by the components $\gamma_{z} z(t-$ $1)_{n}$ and $\gamma_{y} y(t-1)_{n}$ besides the additive and proportional change components. The subsequent latent change in one variable is predicted by the other variable occuring earlier in time in case of coupling between the two univariate LDS models. We investigated different patterns of coupling between two univariate LDS models by restricting the path coefficients in the models. The analyses included models with (i) no coupling $\left(\gamma_{z}=0\right.$ and $\left.\gamma_{y}=0\right)$ between the two series, (ii) unidirectional coupling exists in which one variables predicts later change in the other and vice versa $\left(\gamma_{z}=0\right.$ and $\gamma_{y} \neq 0$ or $\gamma_{z} \neq 0$ and $\left.\gamma_{y}=0\right)$ and (iii) bidirectional coupling exists between the two scores $\left(\gamma_{z} \neq 0\right.$ and $\left.\gamma_{y} \neq 0\right)$. We also compared models with timeinvariant and time-varying coupling coefficients $\gamma_{z}$ and $\gamma_{y}$. Whenever the final model indicated that more than one $\gamma$ coefficent (one per phase of treatment) per process variable was significant, the ceofficencts were tested for significant differences. The third step of our analyses concerns the hypotheses whether treatment condition ( $\mathrm{T}+\mathrm{vs}$. $\mathrm{T}-)$ predicts the subsequent rate of change in the studied variables over the treatment process. Treatment condition is added by the term $(\varphi T X)$ in the equations 2 . All path coefficients are reported as unstandardized coefficients. The parameters of the LDS models were estimated in Mplus version 6.1 (Muthen \& Muthen, 2007). We used the full the full-information maximum 


\section{TIMING MATTERS}

likelihood estimator due to missing data in some cases. This approach ensures the use of all available data for parameter estimation. Thus, also patients with incomplete sessions were incorporated into analyses.

\section{Results}

\section{Baseline Values}

The mean and standard deviations for the outcome variables and process variables at baseline and post-treatment are displayed in Table 1 . The correlations between variables at baseline and post-treatment are likewise displayed in Table 1.

\section{Lower level mediation models}

The association of the five process variables ACQ, BSQ, ASI, MI, AAQ-II and the treatment outcomes PAS and CGI were investigated by lower level mediation models. This preliminary step was conducted in view of the existing literature. ACQ, BSQ, MI, ASI and AAQ-II all partially mediated the treatment outcomes of PAS and CGI as indicated by a significant mediated effect in the mediator analyses (available upon request). However, lower level mediation models are inadequate to show sequencing across time.

The WL reported only negligible pre-treatment to post-treatment changes and was significantly worse than both treatment groups at post-treatment (see Gloster et al., 2011). Nevertheless, the WL was tested here using lower-level models. As expected, the WL group did not demonstrate any meditational effects. As no meaningful change was observed in this group, predicting change was not possible and this group was excluded from further longitudinal analyses below.

\section{Univariate Latent Difference Score Models}

The change in PAS, CGI, ACQ, BSQ, MI, ASI and AAQ-II was investigated by univariate LDS models including the no change model and the two dual change models with both time-varying and time-invariant proportional effects $\beta(t)$. The no change LDS models consistently resulted in a poor model fit (SRMR ranges form .26 for ASI to .42 for AAQ-II). 


\section{TIMING MATTERS}

The univariate LDS models including time-varying proportional effects $\beta(t)$ substantially improved model fit compared to time-invariant proportional effects in all analyzed models. The model fit of the univariate LDS models can be considered to be acceptable for modeling the change in the seven variables over time by a dual change model with time-varying proportional effects (CFI ranges from .86 for CGI to .98 for ASI; TLI ranges from .84 for MI to .98 for AAQ-II; RMSEA ranges from .08 for AAQ-II and MI to .14 for CGI; SRMR ranges from .04 for ASI to .10 for MI). Unstandardized parameter estimates for the proportional effects $\beta(t)$ were statistically significant (ps ranging from <.001 to .043) except for the BSQ and MI. The latent BSQ $\left(\beta_{1}=-.12, \mathrm{p}=.35\right)$ and $\mathrm{MI}\left(\beta_{1}=-.15, \mathrm{p}=.10\right)$ at baseline assessment did not significantly predict the subsequent rate of change. Detailed information is reported in table 2 about model fit and parameter estimates for the additive additive and proportional change components.

\section{Bivariate Latent Difference Score Models}

The parameter estimates and the model fit indices are reported in table 3 for the final bivariate LDS models. The final models were selected based on considering a combination of the Bayesian information criterion (BIC), the comparative fit index (CFI), the Tucker-Lewis index (TLI), root-mean-square error of approximation (RMSEA) and standardized root mean square residual (SRMR).

Panic and agoraphobia symptoms. Five bivariate LDS models were conducted for evaluating the coupling between the univariate series of PAS and ACQ, BSQ, ASI, MI and AAQ-II. We compared four models for each variable combination, where (i) no coupling exists, (ii) unidirectional coupling from PAS to the process variable, (iii) unidirectional coupling from the process variable to PAS and (iv) bidirectional coupling between PAS and process variable. Given our results, the bivariate LDS models including unidirectional coupling from ACQ to PAS (SRMR=.05), BSQ to PAS (SRMR=.06) and ASI to PAS $(\mathrm{SRMR}=.03)$ resulted in best model fit. Latent ACQ significantly predicts later change in PAS 


\section{TIMING MATTERS}

for baseline to intermediate ( $\gamma_{\left.1, A C Q_{-} P A S\right)}$, intermediate to post $\left(\gamma_{2}, A C Q_{-} P A S\right)$ and post to follow-up $\left(\gamma_{3}, A C Q_{-} P A S\right)$ assessment. The coupling coefficient $\gamma_{2}, A C Q_{-} P A S$ significantly differs from $\gamma_{3}$, ${ }_{A C Q} P A S\left(\chi^{2}(1)=12.78, \mathrm{p}<.001\right)$, indicating that the strongest association existed for latent ACQ predicts change in PAS at the interval post to follow-up assessment. Latent BSQ did not predict later change in PAS over time. Latent ASI at post assessment predicted later change in PAS $\left(\gamma_{3, A S I}\right.$ PAS $\left.=.28, \mathrm{p}=.02\right)$. The longitudinal association of PAS and MI was best modeled by a bivariate LDS model with time-invariant coupling coefficients (SRMR=.06). Latent MI predicted later change in PAS $\left(\gamma_{1, M I_{-} P A S}=\gamma_{2}, M I_{-} P A S=\gamma_{3, M I_{-} P A S}=11.0, \mathrm{p}<.001\right)$, suggesting the effect of MI was not different across treatment phases. Notably, latent PAS also predicted later change in MI $\left(\gamma_{1, P A S_{-} M I}=\gamma_{2}, P A S_{-} M I=\gamma_{3, P A S_{-} M I}=.13, \mathrm{p}<.001\right)$. The bivariate LDS model with bidirectional coupling and time-varying coupling coefficients for PAS and AAQ-II achieved best model fit (SRMR=.04). Latent AAQ-II predicted later change in PAS in the

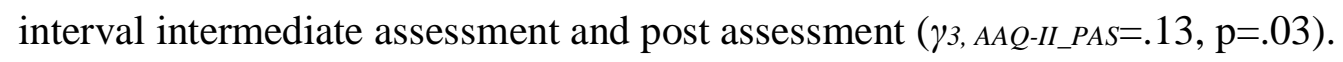

Clinical Functioning. Bivariate LDS models were applied for investigating the associations of CGI and the five process variables over time. The final models included bidirectional coupling coefficients. The alternative bivariate LDS models for CGI and ACQ including no coupling, unidirectional coupling and bidirectional coupling resulted in an acceptable (RMSEA ranges from .12 to .13, SRMR ranges from .17 to .18, CFI is .9, TLI ranges from .81 to .85). The LDS model for CGI and ACQ with the closest fit included coupling coefficients that were constraint to be equal over time. Neither latent ACQ nor CGI predicted later latent change in the other variable. Latent BSQ at post assessment significantly

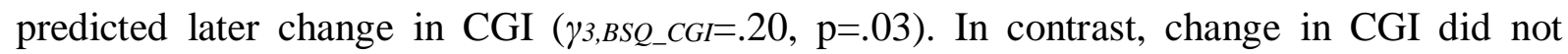
predict later change in BSQ. The best fitting bivariate LDS model for ASI and CGI (SRMR=.04) included bidirectional time-varying coupling coefficients for ASI predicting later change in CGI and time-invariant coupling for CGI predicting later change in ASI. Latent ASI at post assessment predicted later change in CGI $\left(\gamma_{2, A S I} C G I=.06, \mathrm{p}<.001\right)$. Notably, 


\section{TIMING MATTERS}

change in CGI significantly predicted later change in ASI over time $\left(\gamma_{1, C G I_{-} A S I}=\gamma_{2}, C G I_{-} A S I=\gamma_{3}\right.$, CGI_ASI $=5.79, \mathrm{p}<.001)$. The longitudinal association of CGI and MI was best modeled by a bivariate LDS model with time-invariant coupling coefficients (SRMR=.18), suggesting the effect of MI is not significantly different across treatment phases. It is notable that even the best fitting model did not result in a consistent good model fit. The indices CFI $(\mathrm{CFI}=.90)$ and TLI $($ TLI $=.85)$ suggested an acceptable model fit, whereas RMSEA $($ RMSEA $=.14)$ and SRMR (SRMR $=.18)$ suggested a poor model fit. Latent MI predicted later change in CGI $\left(\gamma_{1, M I_{-} C G I}=\gamma_{2}, M I_{-} C G I=\gamma_{3, M I_{-} C G I}=2.58, \mathrm{p}<.001\right)$ and latent CGI also predicted later change in MI $\left(\gamma_{1, C G I \_M I}=\gamma_{2, C G I \_M I}=\gamma_{3, C G I \_M I}=.96, \mathrm{p}<.001\right)$. The bivariate LDS model for AAQ-II and CGI including time-varying coupling coefficients resulted in an acceptable model fit $(\mathrm{SRMR}=.09)$. Latent AAQ-II predicted later change in CGI over time $\left(\gamma_{1, \mathrm{AAQ}-\mathrm{II} \_\mathrm{CGI}}=.40\right.$, $\mathrm{p}=.008 ; \gamma_{2}$,AAQ-II_CGI $=.43, \mathrm{p}=.01 ; \gamma_{3}$, AAQ-II_CGI $\left.=.47, \mathrm{p}<.014\right)$ and vice versa $\left(\gamma_{1, \text { CGI_AAQ-II }}=9.4\right.$, $\mathrm{p}=.004 ; \gamma_{2}$, CGI_AAQ-II $=8.5, \mathrm{p}=.011 ; \gamma_{3}$, CGI_AAQ-II $\left.=6.1, \mathrm{p}=.028\right)$. Although the three coupling coefficients for latent AAQ-II predicting later change in CGI differed, these differences were not significantly different throughout treatment.

Treatment condition. We tested whether the treatment condition in our study ( $\mathrm{T}+\mathrm{vs}$. T-) predicted the rate of change in outcome and process variables. We added treatment condition to the best fitting bivariate LDS model as presented in table 3. For example, treatment condition was established as a predictor for the rate of change in ACQ in the bivariate LDS model for ACQ and PAS with unidirectional coupling (latent ACQ predicts later change in PAS). The goodness-of-fit parameters indicate a good model fit $\left(\chi^{2}(23)=41.2\right.$, $\mathrm{p}=.01 ; \mathrm{CFI}=.98 ; \mathrm{TLI}=.97 ; \mathrm{RMSEA}=.05 ; \mathrm{SRMR}=.05)$. However, treatment condition did not significantly predict change in ACQ throughout treatment $\left(\varphi_{1}=-.02, \mathrm{p}=.88 ; \varphi_{2}=.21\right.$, $\left.\mathrm{p}=.79 ; \varphi_{3}=1.60, \mathrm{p}=.07\right)$. A similar pattern was found for the other biavariate LDS models with treatment condition as an additional explanatory variable.

\section{Discussion}




\section{TIMING MATTERS}

This study examined the mechanism of action in CBT for Panic Disorder with Agoraphobia using temporally sensitive bivariate latent difference score modeling in a large sample of 301 patients. Importantly, the current study found evidence for the temporal specificity of process-outcome effects over the course of therapy and differences between outcome measures. Change in a comprehensive measure of panic and agoraphobic symptoms (PAS) was consistently predicted across all phases of treatment by previous values of catastrophic appraisal (ACQ) and agoraphobic avoidance (MI). In contrast to the unidirectional relationship from ACQ to subsequent scores on the PAS, the relation between MI and PAS was bidirectional (i.e., scores on the PAS also predicted subsequent change on the MI). During the second phase of treatment (i.e., exposure in situ), scores on psychological flexibility (AAQ-II) predicted subsequent change in the PAS at post-treatment. This suggests that psychological flexibility is particularly relevant during the phase of treatment that patients are asked to face their fears. Further changes on the PAS during the 6-month followup period were unidirectionally associated with scores on the ASI at post-treatment. Fear of bodily symptoms (BSQ) did not predict subsequent change in the PAS during any stage of therapy.

Change in global functioning (CGI) presented a somewhat different picture. Scores in both agoraphobic avoidance (MI) and psychological flexibility (AAQ-II) predicted subsequent change in functioning across all phases of treatment. Likewise, scores on the CGI predicted subsequent changes in the MI and AAQ-II during these phases (bidirectional relations). This suggests that both avoidance and psychological flexibility are strongly related to functioning across the therapy and follow-up periods and are complexly intertwined with functioning. In addition, scores on anxiety sensitivity (ASI) at baseline predicted subsequent change in functioning from pre-treatment to post-treatment, as did functioning predict subsequent change in anxiety sensitivity (bi-directional relation). These bi-directional relationships may be similar to those observed by Teachman, Marker, \& Clerkin (2010) with 


\section{TIMING MATTERS}

the variables distress/ apprehension. The only unidirectional relation with functioning was observed for scores on the fear of bodily symptoms (BSQ) at post-treatment for subsequent change in functioning between post-treatment and follow-up. Catastrophic appraisal (ACQ) did not predict subsequent change in functioning at any point during the study.

Taken together, our hypotheses were partially supported. In partial contrast to our hypothesis, cognitive appraisal predicted subsequent change in panic and agoraphobia symptoms across all time points and not just during sessions 1-4. Consistent with our hypothesis, cognitive appraisal did not predict subsequent change in functioning. Contrary to our hypothesis, anxiety elicited by bodily symptoms did not predict subsequent change in panic symptoms at any time point and did predict subsequent functioning at the follow up assessment. Contrary to our hypothesis, anxiety sensitivity predicted subsequent panic and agoraphobia symptoms only during the follow-up period. However, consistent with our hypothesis, anxiety sensitivity was related to functioning during the treatment phase.

Consistent with our hypotheses, avoidance behavior was related to subsequent change in panic symptoms and functioning across all phases. Also consistent with our hypothesis, psychological flexibility predicted subsequent change in panic symptoms during sessions 5-12 and functioning across all time points.

This research builds on previous studies, all of which used panic and/ or agoraphobic symptoms as an outcome variable. Although some of these studies largely lacked prospective temporal designs that measured process variables and outcome measures longitudinally (see Meuret et al., 2010, Teachman et al., 2010 for exceptions), results from these studies help piece together the puzzle of the processes relevant for effective treatment. Indeed, our results are consistent with the reliable finding that measures of one's appraisal of symptoms (e.g., ACQ, BSQ, and ASI) mediated or partially mediated outcome (Casey et al., 2005; Smits et al., 2004; Meuret et al., 2010; Hofmann et al., 2007; Voegele et al., 2010; Meulenbeek et al., 2010). This finding was also found in studies that used different analytical frameworks such 


\section{TIMING MATTERS}

as time series analysis (Bouchard et al., 2007) structural equation modeling (Hoffart, Sexton, Hedley, \& Martinsen, 2008), and bivariate latent difference score modeling (Teachman, Marker, \& Clerkin, 2010).

The longitudinal analysis used in the current study advance our understanding of when and to some degree how the consistent finding that one's appraisals of panic and agoraphobic symptoms mediates outcome. Consistent with previous studies, results of the current study suggest that panic symptomatology is affected by one's catastrophic beliefs (ACQ) during all phases of treatment. These analyses also suggest that this effect is strongest during the generalization phase. Similarly, agoraphobic avoidance is associated with subsequent change in PAS across treatment. Interestingly, psychological flexibility seems to affect panic symptomatology during the in situ exposure phase of treatment. This would suggest that exposure in situ requires a patient to engage with the feared stimuli in a flexible manner and take steps to reduce avoidance behavior (see Gloster et al., 2012). During the follow-up period, agoraphobic avoidance, catastrophic cognitions, and fear of fear are the salient process variables. In sum, whereas cognitive variables do affect panic and agoraphobic-related outcome, the present results suggest that not all cognitive variables predict outcome, and which cognitive variables are the most salient predictors depends on the phase of treatment. However, given their exploratory nature these findings clearly require replication before firm conclusions can be drawn.

We also found evidence for the process of change in two variables not previously tested. First, the degree of self-reported situational agoraphobic avoidance (MI) was most consistently associated with the reduction in panic and agoraphobic symptoms and functioning. The bidirectional relation suggests a complex relation between these variables, likely due in part to a partial overlap of the constructs. It is important to note that two previous mediation studies included agoraphobic avoidance in their analyses but treated it as a dependent variable (Vögele et al, 2010; Meulenbeek et al., 2010). We treated agoraphobic 


\section{TIMING MATTERS}

avoidance as a potential process variable, however, because the treatment conceptualized avoidance and safety behaviors as a maintaining variable and directly targeted them (both those publically observable and those only observable to the patient). As such, the mobility inventory captured one class of this behavior. The final process variable associated with changes in the outcome was psychological flexibility (AAQ-II). This variable is not specific to panic and agoraphobia and the AAQ-II does not contain any words specifically referring to panic or agoraphobia. Instead, it is a broader construct that measures the degree to which one can mindfully accept thoughts and emotions while engaging in one's life when it is important to do so. As such, it is theoretically consistent that psychological flexibility was associated with change in panic and agoraphobia symptoms only during the phase of treatment that concentrated on exposure in situ but not the phase that concentrated on psychoeducation (Gloster, Hummel, Lydmirskya, Hauke, \& Sonntag, 2012): dropping subtle avoidance behaviors and mindfully accepting associated thoughts and emotions promotes change. It is likewise theoretically consistent that psychological flexibility was consistently related to subsequent change in functioning: promotion of psychological flexibility increases one's ability to engage with that which is important to the patient.

This study also expanded the examination of process variables on the outcome of global functioning. In addition to adding information about how the putative process variables affect a broader target, testing the process variables against the CGI also served as a test of specificity for the process variables. The variables associated with the change in global functioning were agoraphobic avoidance and psychological flexibility across all treatment phases; anxiety sensitivity during the active phase of treatment; and fear of bodily symptoms during the generalization phase of treatment. Interestingly, the cognitive appraisal process variables that have consistently been found to be associated with change in panic and agoraphobic symptoms were no longer significantly related to global functioning in the longitudinal models and only anxiety sensitivity was related to change in functioning during 


\section{TIMING MATTERS}

the active treatment phase. This, therefore, partially supports and is simultaneously in partial contrast to Smits et al., 2004, who found that anxiety sensitivity statistically mediated functioning in a cross-sectional analysis. Differences may have resulted from the timing of measurements (concurrent measurement at pre and post vs. longitudinal), measurement format (clinician judgment in the present study versus questionnaire in Smits et al., 2004), differences in the treatment, or a combination of these factors. Once again, there is a critical need for replications before the processes that lead to change in global functioning can be established. Results clearly point to crucial importance of testing across various definitions of outcome and especially of expanding beyond purely symptom-based definitions. If replicated, these results suggest that different processes are involved in the change of symptomatology and functioning across the various treatment phases.

Treatment group ( $\mathrm{T}+\mathrm{vs}$. $\mathrm{T}-$ ) did not contribute to the explanation of relation between processes and outcome and were not included in the final models. This suggests that despite the slight advantage seen by the T+ group in outcome (Gloster et al., 2001), both treatment variants seem to work through the same processes. This is not surprising as both treatment variants had identical content and differed only with respect to the therapist's presence during exposure in situ. It remains a possibility that the presence of the therapist may have facilitated the dropping of safety behaviors or offered more intense guidance, but the sum total of such effects - if they do indeed exist - are not strong enough to be detected by these analyses.

By linking process-outcome effects with specific phases and elements of treatment, we are in a stronger position to tie together results from outcome trials with current theories about the mechanisms that underlie treatment. For example, inhibitory learning that promotes tolerance of anxiety and develops competing non-threat expectancies and that can be generalized across contexts is believed to be a crucial mechanism in exposure therapy (Arch \& Craske, 2008). This study, then, shows with temporal fidelity that some of the therapeutic techniques and processes are involved at different time points during the therapy and may 


\section{TIMING MATTERS}

point to a specification of what is involved in the processes of inhibitory learning. That is, during the intensive exposure in situ phase of treatment, cognitive attribution, agoraphobic avoidance and psychological flexibility are associated with changes in PD/AG severity whereas changes in global functioning are associated with agoraphobic avoidance, psychological flexibility, and anxiety sensitivity. Although clearly in need of replication in other variations of CBT for PD/AG, this type of analysis aids in the understanding of treatment processes at specific level.

This study needs to be interpreted in the light of several limitations. First, although consistent with previous studies, the process variables examined in this study were assessed using questionnaires are limited by the retrospective recall bias inherent in questionnaires. Future studies using additional methodologies (e.g., ecological momentary assessment, physiological variables, etc.; e.g., Domschke et al., 2010; Kircher et al., in press; Richter et al., in press), with different sources of method variance are clearly needed. Second, although we broke down the effects of time across our treatment, the effects of time and the treatment components that occurred during that period of the treatment cannot be parceled apart. Third, the ASI was not administered during the intermediate assessment. Further, the original ASI was utilized in this study. Subsequent versions of the ASI have expanded the measure and emphasized its multidimensional aspects (Taylor \& Cox, 1998; Taylor et al., 2007). Although all versions of the ASI target the overarching concept of anxiety sensitivity, results from this study do not inform about dimensions of anxiety sensitivity as accentuated in more recent versions of the ASI. Likewise, these results cannot speak to the taxonic structure of the ASI. Fourth, although agoraphobic avoidance was revealed to be of core relevance in these analyses, other subtle aspects of avoidance such as cognitive avoidance, utilization of safety signals, etc. were not specifically assessed and therefore the relevance of these and other unassessed factors could not be modeled. Fifth, the examined process variables as well as the outcome variables are not without overlap. Whereas this not unique to this study, construct 


\section{TIMING MATTERS}

overlap is extremely difficult to avoid in psychological research. To test the robustness of these results, we modeled several variations (i.e., with and without inclusion of the avoidance subscale on the PAS) and did not find any noticeable affect on the pattern of results. Sixth, it should be noted that not even sophisticated statistical analyses such as bivariate latent difference score modeling can establish the theoretical concepts, processes, and theories under investigation. Instead, statistical analysis is one approach to examining the process-outcome relations (Kenny, Korchmaros, \& Bolger, 2003; McArdle \& Nesselroade, 1994). Finally, although the study from which these data are derived was partly designed to facilitate these types of analyses (i.e., assessment strategy) and had significantly more power than previous studies, the study did not randomize across the theoretical concepts under consideration. As such, the results should be considered post-hoc in nature and appropriate caution should be used in their interpretation.

Using bivariate latent difference score modeling, this study contributed to the understanding of processes underlying treatment in several ways. First, we replicated the importance of attribution variables consistently implicated in the process-outcome relationships in previous studies. Second, we expanded the list of process variables to agoraphobic avoidance and psychological flexibility. Third, we found clear evidence for the differentiation of meditational effects across outcomes (symptomatology vs. functioning). Finally, and most importantly, we found evidence that putative process variables are associated with changes in outcomes differently at different stages in the treatment. Increasing the time resolution under investigation allows for a better understanding of how processes unfold over time by overcoming a limitation of cross-sectional data. Namely, that they leave open the possibility that multiple constructs are relevant, but that they exert their effect at different points of time during therapy. The results in this study and similar studies have the potential to augment the effects of our current treatment and help therapists better deliver the treatments. The results point to specific processes at work and the timing of these processes. 


\section{TIMING MATTERS}

If substantiated within and across disorders, results like these may help the sizeable minority of patients who do not respond (Hofmann \& Smits, 2008) and/or potentially improve the long-term prospects of patients, which is currently unclear (Durham et al., 2005.) 


\section{TIMING MATTERS}

\section{References}

American Psychiatric Association. (2000). Diagnostic and statistica manual of mental disorders ( $4^{\text {th }}$ ed., text rev.). Washington, DC: Author.

Arch, J. J. \& Craske, M. G. (2008). Acceptance and commitment therapy and cognitive behavioral therapy for anxiety disorders: Different treatments, similar mechanisms? Clinical Psychology: Science and Practice, 15, 263-279.

Bandelow, B. (1995). Assessing the Efficacy of Treatments for Panic Disorder and Agoraphobia. 2. The Panic and Agoraphobia Scale. International Clinical Psychopharmacology, 10(2), 73-81. doi:10.1097/00004850-199506000-00003

Barlow, D. H., Gorman, J. M., Shear, M. K., \& Woods, S. W. (2000). Cognitive-behavioral therapy, imipramine, or their combination for panic disorder: A randomized controlled trial. JAMA, 283, 2529-2536. doi:10.1001/jama.283.19.2529

Baron, R. M., \& Kenny, D. A. (1986). The moderator-mediator variable distinction in social psychological research: Conceptual, strategic, and statistical considerations. Journal of Personality and Social Psychology, 51(6), 1173-1182. doi:10.1037/00223514.51.6.1173

Bond, F., Hayes, S., Baer, R., Carpenter, K., Guenole, N., Orcutt, H., . . Zettle, R.D. (in press). Preliminary psychometric properties of the Acceptance and Action Questionnaire - II: A revised measure of psychological flexibility and experiential avoidance. Behavior Therapy.

Bouchard, S., Gauthier, J., Nouwen, A., Ivers, H., Vallières, A., Simard, S., \& Fournier, T. (2007). Temporal relationship between dysfunctional beliefs, self-efficacy and panic apprehension in the treatment of panic disorder with agoraphobia. Journal of Behavior Therapy and Experimental Psychiatry, 38, 275-292. 


\section{TIMING MATTERS}

Casey, L. M., Newcombe, P. A., \& Oei, T. P. S. (2005). Cognitive mediation of panic severity: The role of catastrophic misinterpretation of bodily sensations and panic selfefficacy. Cognitive Therapy and Research, 29, 187-200.

Chambless, D., Caputo, G., Jasin, S., Gracely, E., \& Williams, C. (1985). The Mobility Inventory for Agoraphobia. Behaviour Research and Therapy, 23(1), 35-44. doi:10.1016/0005-7967(85)90140-8

Chambless, D. L., Caputo, G. C., Bright, P., \& Gallagher, R. (1984). Assessment of fear of fear in agoraphobics: The Body Sensations Questionnaire and the Agoraphobic Cognitions Questionnaire. Journal of Consulting and Clinical Psychology, 52(6), 1090-1097. doi:10.1037/0022-006X.52.6.1090

Clark, D. A. (1986). A cognitive approach to panic. Behaviour Research and Therapy, 24, 461-470.

Domschke, K., Reif, A., Weber, H., Richter, J., Hohoff, C., Ohrmann, P., ... Deckert, J. (2010). Neuropeptide S Receptor Gene-Converging Evidence for a Role in Panic Disorder. Molecular Psychiatry, 1-11.

Durham, R. C., Higgins, C., Chambers, J. A., Swan, J. S., \& Dow, M. G. (2011). Long-term outcome of eight clinical trials of CBT for anxiety disorders: Symptom profile of sustained recovery and treatment-resistant groups. Journal of Affective Disorders, 136, 875-881.

Ehlers, A. (1995). A 1-year prospective study of panic attacks: Clinical course and factors associated with maintenance. Journal of Abnormal Psychology, 104, 164-172.

Forman, E. M., Herbert, J. D., Moitra, E., Yeomans, P. D., \& Geller, P. A. (2007). A Randomized Controlled Effectiveness Trial of Acceptance and Commitment Therapy and Cognitive Therapy for Anxiety and Depression. Behavior Modification, 31(6), 772 -799. doi:10.1177/0145445507302202 


\section{TIMING MATTERS}

Gloster, A., Klotsche, J., Chaker, S., Hummel, K., \& Hoyer J. (2011). Assessing psychological flexibility: What does it add above and beyond existing constructs? Psychological Assessment, 23, 970-982. doi:10.1037/a0024135.

Gloster, A.T., Hummel, K. V., Lyudmirskaya, I., Hauke, T. \& Sonntag, R. F. (2012). Aspects of Exposure Therapy in Acceptance and Commitment Therapy. In: P. Neudeck, \& H.U. Wittchen. Exposure Therapy: Rethinking the Model - Refining the Method (pp. 127-152). New York: Springer.

Gloster, A., Wittchen, H., Einsle, F, Hofler, M., Lang, T, Helbig-Lang, S,. . . Arolt, V. (2009). Mechanism of action in CBT (MAC): methods of a multi-center randomized controlled trial in 369 patients with panic disorder and agoraphobia. European Archives of Psychiatry and Clinical Neuroscience, 259, 155-166. doi:10.1007/s00406009-0065-6

Gloster, A. T., Wittchen, H.-U., Einsle, F., Lang, T., Helbig-Lang, S., Fydrich, T.,. . Arolt, V. (2011). Psychological treatment for panic disorder with agoraphobia: A randomized controlled trial to examine the role of therapist-guided exposure in situ in CBT. Journal of Consulting and Clinical Psychology, 79(3), 406-420. doi:10.1037/a0023584

Guy, W. (1976). ECDEU assessment manual for psychopharmacology. Rockville, MD: US Department of Health, Education, and Welfare.

Hawley, L. L., Ho, M. H., Zuroff, D. C., \& Blatt, S. J. (2006). The relationship of perfectionism, depression, and therapeutic alliance during treatment for depression: Latent difference score analysis. Journal of Consulting and Clinical Psychology, 74, 930-942.

Hoffart, A. (1995). Cognitive mediators of situational fear in agoraphobia. Journal of Behavior Therapy and Experimental Psychiatry, 26, 313-320. 


\section{TIMING MATTERS}

Hoffart, A., Sexton, H., Hedley, L., \& Martinsen, E. (2008). Mechanisms of change in cognitive therapy for panic disorder with agoraphobia. Journal of Behavior Therapy and Experimental Psychiatry, 39(3), 262-275. doi:10.1016/j.jbtep.2007.07.006

Hofmann, S. G. \& Smits, J. A. J. (2008). Cognitive-behavioral therapy for adult anxiety disorders: A meta-analysis of randomized placebo-controlled trials. Journal of Clinical Psychiatry, 69, 621-632.

Hofmann, S. G., Meuret, A. E., Rosenfield, D., Suvak, M. K., Barlow, D. H., Gorman, J. M., Shear, M. K., u. a. (2007). Preliminary evidence for cognitive mediation during cognitive-behavioral therapy of panic disorder. Journal of Consulting and Clinical Psychology, 75(3), 374-379. doi:10.1037/0022-006X.75.3.374

Hofmann, S. G. \& Spiegel, D. A. (1999). Panic control treatment and its applications. Journal of Psychotherapy Practice and Research, 8, 3-11.

Kämpfe, C. K., Gloster, A. T., Wittchen, H.-U., Helbig-Lang, S., Lang, T., Gerlach, A. L., ...Deckert, J. (2012). Experiential avoidance and anxiety sensitivity in patients with panic disorder and agoraphobia: Do both constructs measure the same? International Journal of Clinical and Health Psychology, 12.

Kashdan, T. B, Zvolensky, M. J., \& McLeish, A. C. (2008). Anxiety sensitivity and affect regulatory strategies: Individual and interactive risk factors for anxiety-related symptoms. Journal of Anxiety Disorders, 22, 429-440.

Karekla, M., Forsyth, J. P., \& Kelly, M. M. (2004). Emotional avoidance and panicogenic responding to a biological challenge procedure. Behavior Therapy, 35(4), 725-746.

Kazdin, A. E. (2007). Mediators and Mechanisms of Change in Psychotherapy Research. Annual Review of Clinical Psychology, 3(1), 1-27. doi:10.1146/annurev.clinpsy.3.022806.091432

Kenny, D. A., Korchmaros, J. D., \& Bolger, N. (2003). Lower Level Mediation in Multilevel Models. Psychological Methods, 8(2), 115-128. 


\section{TIMING MATTERS}

Kircher, T., Arolt, V., Jansen, A., Pyka, M., Reinhardt, I., Kellermann, T., ... Straube, B. (2013). Effect of cognitive behavioural therapy on neural correlates of fear conditioning in panic disorder, Biological Psychiatry, 73, 93-101.

Lang, T., Helbig-Lang, S., Westphal, D., Gloster, A. T., \& Wittchen, H.U. (2011). Expositionsbasierte Therapie der Panikstörung mit Agoraphobie: Ein Behandlungsmanual [Exposure-based Therapie for Panic Disorder with Agoraphobia: A Treatment Manual]. Hogrefe: Göttingen.

McArdle, J. J., \& Nesselroade, J. R. (1994). Using multivariate data to structure developmental change. In S. H. Cohen \& H. W. Reese (Eds.), Life-span developmental psychology: Methodological contributions (pp. 223-267). Hillsdale, NJ: Lawrence Erlbaum Associates.

Meulenbeek, P., Spinhoven, P., Smit, F., Van Balkom, A., \& Cuijpers, P. (2010). Cognitive mediation of panic reduction during an early intervention for panic. Acta Psychiatrica Scandinavica, 122(1), 20-29. doi:10.1111/j.1600-0447.2009.01530.x

Meuret, A. E., Rosenfield, D., Seidel, A., Bhaskara, L., \& Hofmann, S. G. (2010). Respiratory and cognitive mediators of treatment change in panic disorder: Evidence for intervention specificity. Journal of Consulting and Clinical Psychology, 78(5), 691704. doi:10.1037/a0019552

Muthen, B. \& Muthen, L. (2011). Mplus version 6.1 software users guide.1998-2008

Peterson, R., \& Reiss, S. (1993). Anxiety Sensitivity Index Revised Test Manual. Washington, OH: IDS Publishing Corporation.

Preacher, K. J., \& Hayes, A. F. (2008). Asymptotic and resampling strategies for assessing and comparing indirect effects in multiple mediator models. Behavior Research Methods, 40, 879-891.

Richter, J., Hamm, A. O., Pané-Farré, C.A., Gerlach, A. L., Gloster, A. T., Wittchen, H.U., ... Arolt, V. (2012). Dynamics of defensive reactivity in patients with panic disorder 


\section{TIMING MATTERS}

and agoraphobia: Implications for the etiology of panic disorder, Biological Psychiatry, 72, 512-520.

Rodriguez, B. F., Bruce, S. E., Pagano, M. E., Spencer, M. A., \& Keller, M.P. (2004). Factor structure and stability of the Anxiety Sensitivity Index in a longitudinal study of anxiety disorder patients. Behaviour_Research and Therapy, 42, 79-91.

Selig, J. P., \& Preacher, K. J. (2009). Mediation models for longitudinal data in developmental research. Research in Human Development, 6, 144-164.

Singer J.D. \& Willett, J.B. (2003). Applied Longitudinal Data Analysis. Oxford, UK: Oxford University Press.

Smits, J. A. J., Powers, M. B., Cho, Y.R., \& Telch, M. J. (2004). Mechanism of Change in Cognitive-Behavioral Treatment of Panic Disorder: Evidence for the Fear of Fear Mediational Hypothesis. Journal of Consulting and Clinical Psychology, 72(4), 646652. doi:10.1037/0022-006X.72.4.646

Taylor, S. \& Cox, B.J. (1998). An expanded anxiety sensitivity index: evidence for a hierarchic structure in a clinical sample. Journal of Anxiety Disorders, 12, 463-83.

Taylor, S., Zvolensky, M.J., Cox, B.J., Deacon, B., Heimberg, R.G., Ledley, D.R.,... Cardenas, S.J. (2007). Robust dimensions of anxiety sensitivity: development and initial validation of the Anxiety Sensitivity Index-3. Psychological Assessment, 19, 176-88.

Teachman, B. A., Marker, C. D., \& Clerkin, E. M. (2010). Catastrophic misinterpretations as a predictor of symptom change during treatment for panic disorder. Journal of Consulting and Clinical Psychology, 78, 964-973. doi:10.1037/a0021067.

Vögele, C., Ehlers, A., Meyer, A. H., Frank, M., Hahlweg, K., \& Margraf, J. (2010). Cognitive mediation of clinical improvement after intensive exposure therapy of agoraphobia and social phobia. Depression and Anxiety, 27(3), 294-301. doi:10.1002/da.20651 


\section{TIMING MATTERS}

Wittchen, H., Gloster, A., Beesdo-Baum, K., Fava, G., \& Craske, M. (2010). Agoraphobia: a review of the diagnostic classificatory position and criteria. Depression and Anxiety, 27(2), 113-133.

Wittchen, H., Nocon, A., Beesdo, K., Pine, D., Hoefler, M., Lieb, R., \& Gloster, A. (2008). Agoraphobia and panic. Psychotherapy and Psychosomatics, 77(3), 147-157.

Zgourides, G. D., Warren, R., \& Englert, M. E. (1989). Further evidence of construct validity for the agoraphobic cognitions questionnaire and the body sensations questionnaire. Psychological Reports, 64, 590.

Zwolensky, M. J. \& Forsyth, J. P. (2002). Anxiety sensitivity dimensions in the prediction of body vigilance and emotional avoidance. Cognitive Therapy and Research, 26, 449460. 
TIMING MATTERS

Table 1: Distribution Outcome and Process Variables at Baseline and Post-assessment and Correlations Between Variables

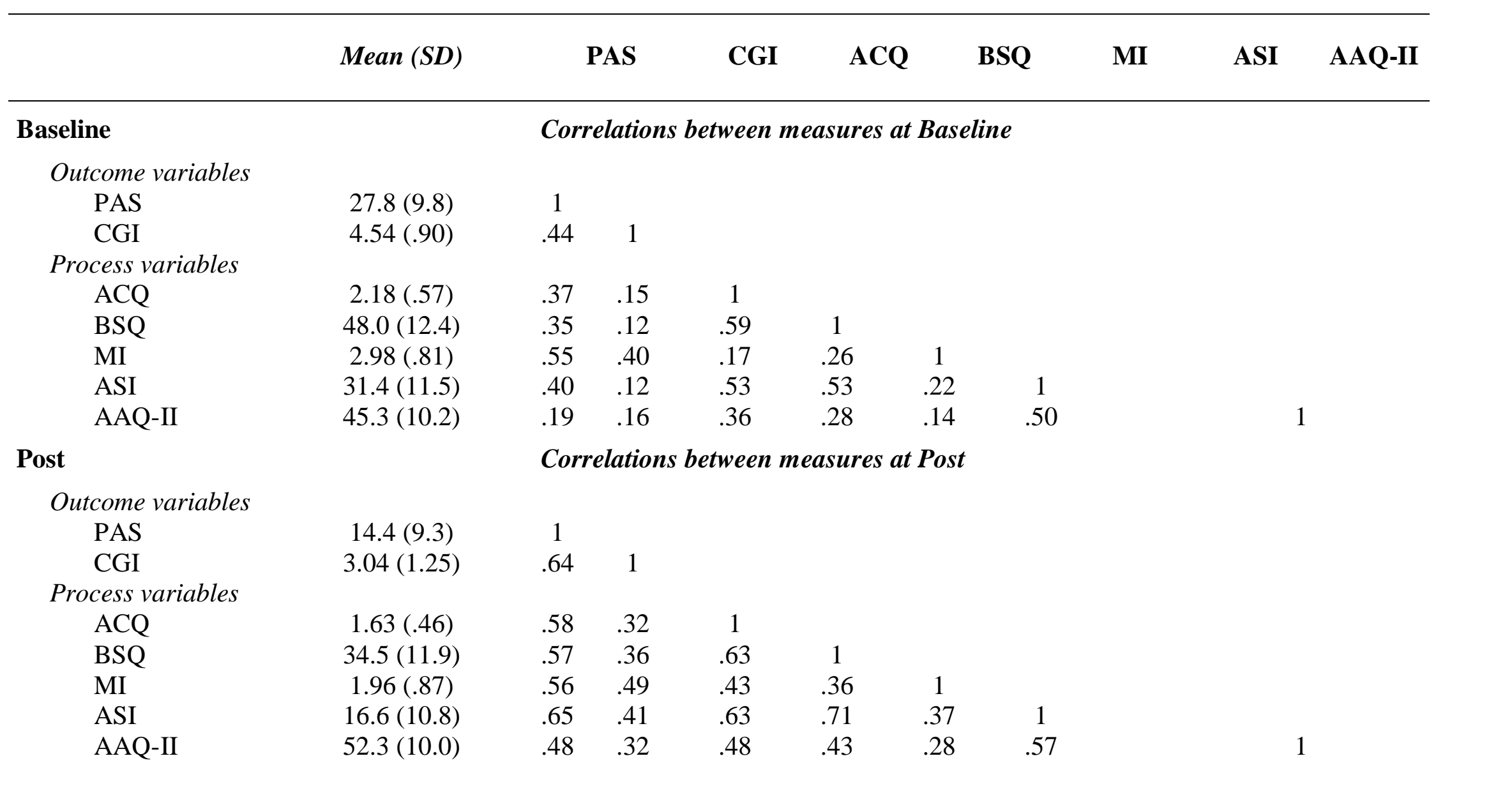

All correlations are significant at the 5\% level; PAS = Panic Agoraphobia Scale; CGI = Clinical Global Impression; ACQ = Agoraphobic Cognitions Questionnaire $; \mathrm{BSQ}=$ Bodily Sensations Questionnaire; ASI = Anxiety Sensitivity Inventory; MI = Mobility Inventory; AAQ-II = Acceptance and Action Questionnaire - II 
Table 2: Univariate LDS models for PAS, CGI, ACQ, BSQ, ASI, MI and AAQ-II

$\begin{array}{llllll}\text { PAS } & \text { CGI } & \text { ACQ } & \text { BSQ } & \text { ASI } & \text { MI }\end{array}$

\begin{tabular}{|c|c|c|c|c|c|c|c|}
\hline \multicolumn{8}{|c|}{ Additive coefficients } \\
\hline \multicolumn{8}{|c|}{$\mathrm{E}[\mathrm{s}](\mathrm{Se}) ; \mathrm{p}$} \\
\hline $\begin{array}{l}\text { value } \\
\sigma^{2}(s)\end{array}$ & $\begin{array}{c}27.8(.6) ; \mathrm{p}<.001 \\
67.85\end{array}$ & $\begin{array}{c}5.2(.1) ; \mathrm{p}<.001 \\
.32\end{array}$ & $\begin{array}{c}2.2(.03) ; \mathrm{p}<.001 \\
.25\end{array}$ & $\begin{array}{c}48.0(.7) ; \mathrm{p}<.001 \\
102.10\end{array}$ & $\begin{array}{c}31.3(.7) ; \mathrm{p}<.001 \\
122.48\end{array}$ & $\begin{array}{c}3.0(.05) ; \mathrm{p}<.001 \\
.65\end{array}$ & $\begin{array}{c}45.3(.6) ; \mathrm{p}<.001 \\
77.79\end{array}$ \\
\hline \multicolumn{8}{|c|}{ Proportional coefficients } \\
\hline$\beta_{1}(\mathrm{Se}) ; \mathrm{p}$ value & $-.22(.09) ; \mathrm{p}=.021$ & $-.46(.15) ; p=.002$ & $-.38(.11) ; \mathrm{p}=.001$ & $-.12(.13) ; p=.348$ & $-*$ & $-.15(.09) ; \mathrm{p}=.102$ & $-.25(.12) ; \mathrm{p}=.037$ \\
\hline$\beta_{2}(\mathrm{Se}) ; \mathrm{p}$ value & $-.43(.11) ; \mathrm{p}<.001$ & $-.33(.16) ; p=.043$ & $-.56(.12) ; \mathrm{p}<.001$ & $-.34(.13) ; p=.009$ & $-.82(.06) ; \mathrm{p}<.001^{1}$ & $-.37(.10) ; \mathrm{p}<.001$ & $-.39(.16) ; \mathrm{p}=.015$ \\
\hline$\beta_{3}(\mathrm{Se}) ; \mathrm{p}$ value & $-.50(.17) ; p=.004$ & $-.50(.21) ; p=.017$ & $-.57(.15) ; \mathrm{p}<.001$ & $-.20(.15) ; p=.024$ & $-.82(.11) ; \mathrm{p}<.001$ & $-.39(.13) ; p=.003$ & $-.24(.11) ; p=.029$ \\
\hline
\end{tabular}

Goodness of fit parameters

\begin{tabular}{lccccccc}
$\#$ & 9 & 9 & 9 & 9 & 8 & 9 \\
BIC & 7459 & 3066 & 1105 & 7827 & 5670 & 1880 \\
$\mathrm{X}^{2}(\mathrm{df}) ; \mathrm{p}$ value & $21.8(5) ; \mathrm{p}=.001$ & $70.8(5) ; \mathrm{p}=.002$ & $20.3(5) ; \mathrm{p}=.001$ & $22.4(5) ; \mathrm{p}<.001$ & $185.3(3) ; \mathrm{p}<.001$ & $86.0(5) ; \mathrm{p}<.001$ & $14.6(5) ; \mathrm{p}=.01$ \\
CFI & .95 & .86 & .97 & .96 & .98 & .87 \\
TLI & .95 & .86 & .96 & .95 & .94 & .84 \\
RMSEA & .11 & .14 & .10 & .11 & .11 & .04 \\
SRMR & .06 & .09 & .05 & .08 & .04 & .08 \\
\hline
\end{tabular}

PAS = Panic Agoraphobia Scale; CGI = Clinical Global Impression; ACQ = Agoraphobic Cognitions Questionnaire ; BSQ = Bodily Sensations Questionnaire; ASI = Anxiety Sensitivity Inventory; MI = Mobility Inventory; AAQ-II = Acceptance and Action Questionnaire - II; BIC = Bayesian information criterion, CFI = Comparative fit index, TLI = Tucker-Lewis index, RMSEA = Root mean square error of approximation; SRMR = standardized root mean square residual; $\#=$ number of model parameters; $\beta_{1}, \beta_{2}$ and $\beta_{3}$ distinct time-varying proportional change coefficients; - $*$ indicates that the parameter is not estimated due to missing ASI at intermediate assessment; ${ }^{1}$ proportional change coefficient $\beta_{2}$ refers to the interval baseline to post assessment 
Table3: Bivariate LDS models for outcome PAS and process variables ACQ, BSQ, ASI, MI and AAQ-II

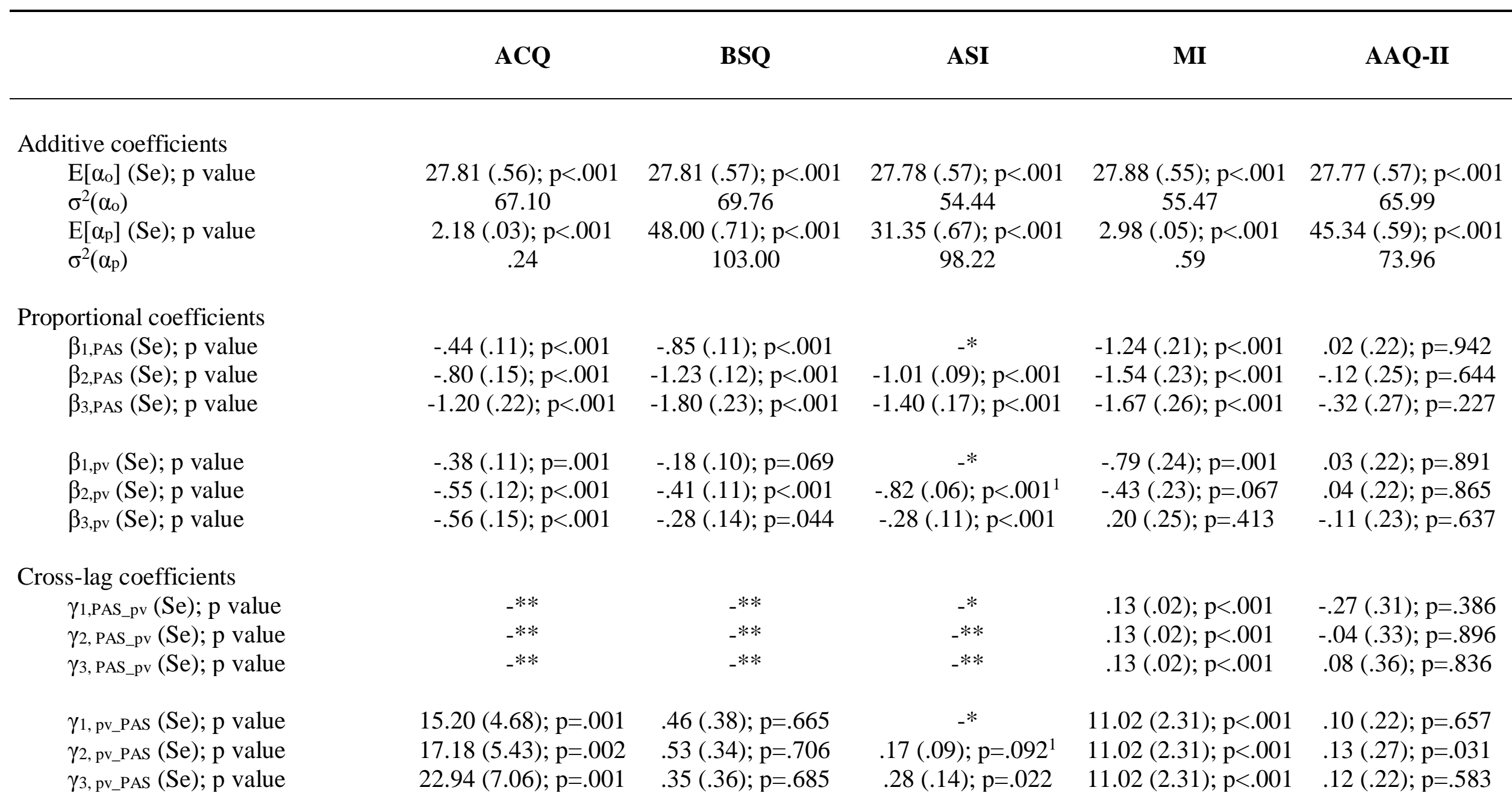

table continues 
TIMING MATTERS

Goodness of fit parameters

$\begin{array}{lccccc}\# & 26 & 26 & 24 & 25 & 29 \\ \text { BIC } & 8339 & 15066 & 10919 & 9082 & 14753 \\ \mathrm{X}^{2}(\mathrm{df}) ; \mathrm{p} \text { value } & 38.1(18) ; \mathrm{p}<.001 & 35.8(18) ; \mathrm{p}<.001 & 7.04(4) ; \mathrm{p}<.134 & 79.5(19) ; \mathrm{p}<.001 & 3.3(15) ; \mathrm{p}<.001 \\ \text { CFI } & .98 & .98 & .97 & 1.00 & .95 \\ \text { TLI } & .97 & .06 & .98 & .93 & .98 \\ \text { RMSEA } & .06 & .06 & .05 & .10 & .97 \\ \text { SRMR } & .05 & & .03 & .06 & .06\end{array}$

PAS = Panic Agoraphobia Scale; ACQ = Agoraphobic Cognitions Questionnaire; BSQ = Bodily Sensations Questionnaire; ASI = Anxiety Sensitivity Inventory; MI = Mobility Inventory; AAQ-II = Acceptance and Action Questionnaire - II; BIC = Bayesian information criterion, CFI = Comparative fit index, TLI = Tucker-Lewis index, RMSEA = Root mean square error of approximation; SRMR = standardized root mean square residual; $\#=$ number of model parameters; $\beta_{1}, \beta_{2}$ and $\beta_{3}$ distinct time-varying proportional change coefficients; $\gamma_{1, P A S}$ ppv, $\gamma_{2, P A S}$ ppv, $\gamma_{3, P A S}$ _pv distinct coupling coefficients for latent PAS predicting later change in process variable; $\gamma_{1, \text { pv_PAS, }} \gamma_{2}$, pv_PAS, $\gamma_{3}$, pv_PAS distinct coupling coefficients for latent process variable predicting later change in PAS; -* indicates that the parameter is not estimated due to missing ASI at intermediate assessment; -** indicates that the parameter was not estimated because during the process of model building better model fit was obtained by excluding the parameter; ${ }^{1}$ proportional change coefficient $\beta_{2}$ refers to the interval baseline to post assessment 
TIMING MATTERS

Table4: Bivariate LDS models for outcome CGI and process variables ACQ, BSQ, ASI, MI and AAQ-II

\begin{tabular}{|c|c|c|c|c|c|}
\hline \multicolumn{6}{|l|}{ Additive coefficients } \\
\hline $\mathrm{E}\left[\alpha_{\mathrm{o}}\right](\mathrm{Se}) ; \mathrm{p}$ value & $5.17(.05) ; \mathrm{p}<.001$ & $5.18(.05) ; \mathrm{p}<.001$ & $5.17(.05) ; \mathrm{p}<.001$ & $5.18(.05) ; \mathrm{p}<.001$ & $5.17(.05) ; \mathrm{p}<.001$ \\
\hline$\sigma^{2}\left(\alpha_{0}\right)$ & .32 & .02 & 1.15 & .26 & .31 \\
\hline $\mathrm{E}\left[\alpha_{\mathrm{p}}\right](\mathrm{Se}) ; \mathrm{p}$ value & $2.18(.03) ; \mathrm{p}<.001$ & $47.98(.70) ; \mathrm{p}<.001$ & $31.37(.66) ; \mathrm{p}<.001$ & $2.99(.05) ; \mathrm{p}<.001$ & $45.33(.59) ; \mathrm{p}<.001$ \\
\hline$\sigma^{2}\left(\alpha_{p}\right)$ & .25 & 94.69 & 55.3 & .56 & 74.05 \\
\hline \multicolumn{6}{|l|}{ Proportional coefficients } \\
\hline$\beta_{1, \mathrm{CGI}}(\mathrm{Se}) ; \mathrm{p}$ value & $-.50(.23) ; p=.025$ & $-2.84(.94) ; \mathrm{p}=.003$ & $-*$ & $-1.47(.37) ; \mathrm{p}<.001$ & $-1.98(.65) ; p=.002$ \\
\hline$\beta_{2, \text { CGI }}(\mathrm{Se}) ; p$ value & $-.37(.23) ; p=.109$ & $-3.39(1.14) ; \mathrm{p}=.003$ & $-1.36(.16) ; \mathrm{p}=.001$ & $-1.63(.37) ; \mathrm{p}<.001$ & $-2.14(.68) ; p=.002$ \\
\hline$\beta_{3, \text { CGI }}(\mathrm{Se}) ; p$ value & $-.53(.26) ; p=.037$ & $-3.34(1.16) ; p=.004$ & $-1.52(.17) ; \mathrm{p}=.001$ & $-1.52(.40) ; \mathrm{p}<.001$ & $-1.44(.54) ; p=.007$ \\
\hline$\beta_{1, \mathrm{pv}}(\mathrm{Se}) ; \mathrm{p}$ value & $-.43(.15) ; p=.004$ & $1.43(.93) ; p=.123$ & $-*$ & $-1.03(.35) ; \mathrm{p}=.003$ & $-.48(.34) ; \mathrm{p}=.155$ \\
\hline$\beta_{2, p v}(S e) ; p$ value & $-.59(.15) ; p<.001$ & 1.53 (1.04); $p=.141$ & $.00(.13) ; p=.982^{1}$ & $-.80(.36) ; p=.025$ & $-.50(.25) ; \mathrm{p}=.047$ \\
\hline
\end{tabular}


Cross-lag coefficients

\begin{tabular}{|c|c|c|c|c|c|}
\hline$\gamma_{1, \text { CGI_pv }}(\mathrm{Se}) ; \mathrm{p}$ value & $.07(.07) ; p=.308$ & $-1.58(6.17) ; p=.086$ & $-*$ & $.96(.24) ; \mathrm{p}<.001$ & $9.36(3.27) ; p=.004$ \\
\hline$\gamma_{2, \text { CGI_pv }}(\mathrm{Se}) ; \mathrm{p}$ value & $.07(.07) ; p=.308$ & $14.01(7.50) ; p=.062$ & $5.79(1.63) ; \mathrm{p}<.001$ & $.96(.24) ; \mathrm{p}<.001$ & $8.52(3.35) ; \mathrm{p}=.011$ \\
\hline$\gamma_{3, \text { CGI_pv }}(\mathrm{Se}) ; \mathrm{p}$ value & $.07(.07) ; p=.308$ & $12.86(7.63) ; \mathrm{p}=.092$ & $5.79(1.63) ; \mathrm{p}<.001$ & $.96(.24) ; \mathrm{p}<.001$ & $6.13(2.79) ; p=.028$ \\
\hline$\gamma_{1, \mathrm{pv} \_\mathrm{CGI}}(\mathrm{Se}) ; \mathrm{p}$ value & $-.23(.61) ; p=.710$ & $.13(.08) ; p=.109$ & $-*$ & $2.58(.49) ; \mathrm{p}<.001$ & $.40(.15) ; p=.008$ \\
\hline$\gamma_{2, \text { pv_CGI }}(\mathrm{Se}) ; \mathrm{p}$ value & $-.23(.61) ; p=.710$ & $.11(.08) ; \mathrm{p}=.191$ & $.06(.02) ; p=.001^{1}$ & $2.58(.49) ; \mathrm{p}<.001$ & $.43(.17) ; p=.010$ \\
\hline$\gamma_{3, \text { pv_CGI }}(\mathrm{Se}) ; \mathrm{p}$ value & $-.23(.61) ; p=.710$ & $.20(.09) ; \mathrm{p}=.031$ & $.05(.05) ; p=.684$ & $2.58(.49) ; \mathrm{p}<.001$ & $.47(.19) ; \mathrm{p}=.014$ \\
\hline \multicolumn{6}{|l|}{ dness of fit parameters } \\
\hline$\#$ & 25 & 29 & 23 & 26 & 26 \\
\hline BIC & 4125 & 10817 & 7967 & 4761 & 10385 \\
\hline $\mathrm{X}^{2}(\mathrm{df}) ; \mathrm{p}$ value & $97.6(19) ; p<.001$ & $45.3(15) ; p<.001$ & $13.2(4) ; p<.011$ & $117.6(18) ; p<.001$ & $6.7(18) ; p<.001$ \\
\hline CFI & .90 & .96 & .98 & .90 & .96 \\
\hline TLI & .85 & .92 & .91 & .85 & .93 \\
\hline RMSEA & .12 & .08 & .09 & .14 & .08 \\
\hline SRMR & .18 & .05 & .04 & .18 & .09 \\
\hline
\end{tabular}

CGI = Clinical Global Impression; ACQ = Agoraphobic Cognitions Questionnaire; BSQ = Bodily Sensations Questionnaire; ASI = Anxiety Sensitivity Inventory; MI = Mobility Inventory; AAQ-II = Acceptance and Action Questionnaire $-\mathrm{II}$; BIC = Bayesian information criterion, CFI = Comparative fit index, TLI = Tucker-Lewis index, RMSEA = Root mean square error of approximation; SRMR = standardized root mean square

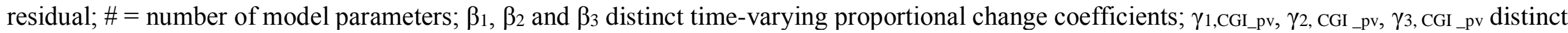

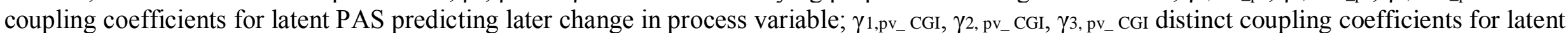
process variable predicting later change in PAS; -* indicates that the parameter is not estimated due to missing ASI at intermediate assessment; ${ }^{1}$ proportional change coefficient $\beta_{2}$ refers to the interval baseline to post assessment 